Review

\title{
Entropy in Urban Systems
}

\section{Pedro Cabral ${ }^{1, *}$, Gabriela Augusto ${ }^{1}$, Mussie Tewolde ${ }^{2}$ and Yikalo Araya ${ }^{3}$}

1 Instituto Superior de Estatística e Gestão de Informação (ISEGI), Universidade Nova de Lisboa, Campus de Campolide, Lisbon 1070-312, Portugal; E-Mail: augusto.gabriela@gmail.com

2 Department of Juvenile Services, State of Maryland, Baltimore, 21201, MD, USA;

E-Mail: mussie.tewolde@maryland.gov

3 Department of Geography, York University, 4700 Keele Street, TO M3J 1P3, Canada;

E-Mail: yikalo@yorku.ca

* Author to whom correspondence should be addressed; E-Mail: pcabral@isegi.unl.pt;

Tel.: +351-213-828-610; Fax: +351-213-828-611.

Received: 23 October 2013; in revised form: 16 November 2013 / Accepted: 25 November 2013 / Published: 27 November 2013

\begin{abstract}
Entropy is a useful concept that has been used to describe the structure and behavior of different systems. We summarize its multifaceted character with regard to its implications for urban sprawl, and propose a framework to apply the concept of entropy to urban sprawl for monitoring and management.
\end{abstract}

Keywords: urban sprawl; spatial entropy; urban systems; entropy monitoring and management framework

\section{Introduction}

The term "entropy" has been used with different meanings in various contexts [1]. The prevailing ambiguity and discussion surrounding entropy and its implications in these various domains is remarkable as the concept is one of the cornerstones of technologies that have defined our globalized civilization regarding transport, communication, and energy transformation. The World's population is concentrated in urban areas that grow larger every day [2], and the uncontrolled expansion of these areas, commonly known as urban sprawl, has tremendous implications for the lives of most of us and for the future of our civilization. 
Cities, urban areas, and urban sprawl are multidimensional systems comprising individuals, communities, society, and economy, in a common geographical location where different types and degrees of interaction occur. Urban sprawl needs spatial-based solutions from urban policy makers to expand utilities, transportation, and other services necessary for social cohesion and the well-being of people. In addition, retailers and leisure companies wish to optimize the locations of their business to attract new clients. These spatial location issues are important topics in the urban sprawl literature [3], and many studies agree that cities are complex systems that evolve as a result of decentralized individual, or small group, decisions instead of through organized, top down planning [4].

The explosive rate of urban sprawl may threaten the ecosystem areas surrounding cities that are often crucial for the quality of life of the cities' inhabitants [2,5]. Various studies have demonstrated the expansion of urban areas into agricultural lands, forest areas, and fragile ecosystems [6-9]. As a result, water and soil are affected by pollution and terrains become vulnerable to landslide [10]. Habitat fragmentation and biodiversity loss have also been addressed in urban sprawl studies [11]. In this paper we review the concept of entropy in urban sprawl studies, while seeking to clarify its uses in urban sprawl studies for monitoring and management.

\section{Entropy Concepts}

The concept of entropy was first proposed in 1867 by the German physicist Rudolph Clausius, who formulated the Second Law of Thermodynamics [12]. The term has its origins in the Greek word $г \rho о \pi \eta$, transformation, where it accounted for the change occurring in a body producing work from heat. Entropy was assigned to the fraction of the energy contained in the body that was unavailable to produce work, corresponding to the transformation-value content of the body in an energy transfer Equation (1):

$$
d S>\frac{d Q}{T}
$$

where $\mathrm{S}$ is entropy, $\mathrm{Q}$ is heat and $\mathrm{T}$ is the body absolute temperature.

The implications of Clausius' work, i.e., that entropy is ever increasing and that energy is always degraded when energy transfer occurs (which somehow measures irreversibility), remain controversial and continue to occupy the attention of the scientific community [1].

Clausius distinguished the transformation content corresponding to the rearrangement of the particles of the body producing work. In 1890 Ludwig Boltzmann used statistical mechanics to describe the thermodynamic properties of a body in which the particles were designated molecules and atoms, along with the arrangement of those particles. It was Max Planck who formulated the Boltzmann entropy expression [13] Equation (2):

$$
S=K \ln W
$$

where $\mathrm{S}$ is entropy, $\mathrm{K}$ the Boltzmann constant and $\mathrm{W}$ the number of possibilities the system can assume, or the number of possible arrangements of its particles.

The greater is the number of possible arrangements, the greater will be entropy, and thus, greater the disorder. Entropy is associated with "disorder", "lower energy quality", and "doom" because 
Clausius stated one of the fundamental laws of the universe: "the entropy of the universe tends to a maximum" [12].

Claude Shannon gave a statistical character to entropy in a new scientific domain: the information theory. His paper "A mathematical theory of Communication" has been considered to be the foundation of modern digital communication and information theory. Shannon defines entropy as an absolute limit of best possible lossless encoding of a digital message [14]. Here, the particles are the bits used to make a symbol and entropy is the logarithm of the possibilities for their arrangement, together with the relative proportion of symbols in the message Equation (3):

$$
H=-\sum p\left(x_{i}\right) \log p\left(x_{i}\right)
$$

where $\mathrm{H}$ is entropy and $p\left(x_{i}\right)$ is the probability of the variable $x$ to assume values of $x_{i} \ldots x_{k}$.

Physicists found that Shannon's entropy had a deeper meaning, independent from thermodynamics, of great significance for statistical mechanics [13].

In 1957 Edwin Thompson Jaynes derived the principle of maximum entropy from Shannon's expression as a new type of subjective statistic inference to set up probabilistic distributions based on partial knowledge [13]. The principle of maximum entropy, allowing the least biased estimation possible, made entropy a concept independent from mechanical hypotheses and coherent with quantum mechanics. Thermodynamic entropy was then reformulated as uncertainty, with the principle of entropy maximization used as a statistical inference method for supporting spatial location and spatial interaction models [3].

In 1962 Leopold and Langbein [15] adapted the thermodynamic concept of entropy to landscape evolution, describing and explaining the geomorphology of a river basin. In their study, entropy is considered in its statistic thermodynamic formulation to assess the energy distribution in a river system. These authors demonstrated that energy will flow to its most probable condition, i.e., a uniform distribution subject only to physical constraints, demonstrating the concept of maximum entropy. The entropy concept is now integrally applied in a geographical context.

The principle of maximum entropy made its entrance into urban studies in 1970 with Alan Wilson in his book "Entropy in Urban and Regional Modeling" [3]. This author proposed a framework for constructing spatial interaction and associated location models. As in [15], he reformulated the gravity associated with transport models to maximum entropy models that estimate urban transport in a maximum entropy environment subject not only to physical but also economic and social constraints. These models proved to be of great importance and applicability in urban planning, from public transport networks to retail locations [3].

In 1972, Henry Theil [16] gave to Shannon entropy a broader interpretation as a measure of dividedness and spatial dispersion in his relative entropy concept. This concept indicates the proportion of the maximum possible dispersion in which a variable is spread between categories or spatial zones (it will be 1 if the variable is evenly spread among all zones, and approaches 0 if the variable is concentrated in a small number of zones) [16]. It is expressed by Equation (4):

$$
H_{n}=\frac{\sum_{1}^{n} p_{1} \log \left(1 / p_{1}\right)}{\log n}
$$


where $\mathrm{H}_{\mathrm{n}}$ is the relative entropy, $p\left(x_{i}\right)$ is the probability of the variable $x$ being found in each of the $n=1, \ldots$ zones, classes or categories.

The relative entropy, also called Shannon equitability index, because of its simplicity, has been of greatest importance as a measure of diversity and evenness for spatial-related issues in fields such as biology, landscape ecology, and urban studies [17].

The concept of entropy in geographical analyses was further refined and enriched by [18], with the definition of spatial entropy. This concept incorporates the spatial variability in the geographical analysis, enabling the optimization of the partition of the study area in zones that are pertinent for the geographical analysis. This author defines spatial entropy as [18] Equation (5):

$$
H=\lim _{\Delta x_{i} \rightarrow 0}-\sum_{i} p_{i} \ln \left(\frac{p_{i}}{\Delta x_{i}}\right)
$$

where $\Delta x_{i}$ is the spatial interval size of the zone $i$ in the study area and $p_{\mathrm{i}}$ the probability of the event.

The spatial structure of urban system emerges with spatial entropy, carrying with it the optimum levels of aggregation for different scales and fractal laws. Moreover, applications of spatial entropy are close to establishing thresholds for the emergence of power laws in dynamic spatial urban systems. These may soon prove to be of the utmost importance in modeling phenomena able to seriously affect the functioning of the urban system.

Maximum entropy models were then introduced into complexity science in the context of urban studies. Batty [4] explored connections between entropy maximizing, substantive interpretation of entropy measures, and spatial distributions produced by longer-term dynamics. The concepts of entropy applicable to urban sprawl studies are no longer restricted to physics or geography. Urban sprawl is not an exclusively geographical phenomenon, it also has socio-economic drivers and consequences.

We mention two very different ways to define entropy in a sociological context, regarding the maximum entropy principle. The original formulation found applicability in sociology in 1990 with Kenneth Bailey's work "Social Entropy Theory" [19]. This author defines social entropy as a correlation in the distribution of population among the subcategories of social variables (e.g., wealth, technology, spatial area, culture, information). The social entropy will be at its minimum when the correlations among variables are maximal (e.g., the same group of individuals has the same level of wealth, lives in the same area, has similar occupations, and has similar cultural values and assets). The entropy increases as the individuals are randomly allocated to the subcategories (e.g., different levels of wealth can be found among individuals with the same occupation). A low level of entropy is necessary to maintain a high standard of living.

An interesting use of entropy in sociology was made by [20]. These authors define the entropy of a social system as a measure of the number of possibilities of a system structure for a given level of energy. In this case, the social system energy accounts for the total resources of the social system (e.g., material assets, skills, knowledge, culture etc.). Like the thermodynamic entropy, it will tend to increase with time, and the likelihood of fluctuations decreases with the size of the social system. In this specific instance, entropy may be interpreted as the level of resilience or adaptability of a social system to internal or external events.

More recently, in the economic field, [21] suggested that property is also subject to the fundamental law of entropy. According to this author, there is a one-directional bias leading toward increasing 
fragmentation, and proposes legal rules to promote functional, legal and physical unity in property. [22] examines the link between urban sprawl and the holdout problem, i.e., "a form of monopoly power that potentially arises in the course of land assembly and urban sprawl". He finds that developers will prefer land whose ownership is less dispersed. Consequently, fragmented land in urban centers is more likely to be underdeveloped, or at a higher state of entropy, because of the holdout problem or problems with strategic bargainers [17].

In Table 1, we summarize the formulations and interpretations of entropy mentioned above. It is representative but not exhaustive.

Table 1. Some of the main contributions of entropy theory to urban studies.

\begin{tabular}{|c|c|c|c|}
\hline Author & Scientific domain & Definition & Interpretation \\
\hline $\begin{array}{c}\text { R. Clausius, } \\
1867[12]\end{array}$ & $\begin{array}{l}\text { Physics- } \\
\text { thermodynamics }\end{array}$ & $\begin{array}{l}\text { Energy in the system not } \\
\text { available to produce work }\end{array}$ & $\begin{array}{l}\text { Unavailable energy tends } \\
\text { to increase }\end{array}$ \\
\hline $\begin{array}{l}\text { Boltzmann-Planck, } \\
1900[13] \\
\end{array}$ & Statistical mechanics & $\begin{array}{l}\text { Possibilities of arrangement } \\
\text { of molecules }\end{array}$ & Disorder \\
\hline $\begin{array}{c}\text { C. Shannon, } \\
1948[14]\end{array}$ & Information theory & $\begin{array}{l}\text { Average number of bits necessary } \\
\text { to communicate a symbol }\end{array}$ & Uncertainty \\
\hline $\begin{array}{l}\text { E. Jaynes, } \\
1957[13]\end{array}$ & Statistical mechanics & $\begin{array}{l}\text { Principle of maximum entropy, } \\
\text { where everything goes } \\
\text { everywhere unless constraints } \\
\text { are imposed }\end{array}$ & Statistic inference \\
\hline $\begin{array}{l}\text { Leopold and Langbein, } \\
\qquad 1962[15]\end{array}$ & $\begin{array}{c}\text { Hydrologic and } \\
\text { geomorphic sciences }\end{array}$ & $\begin{array}{l}\text { Entropy in landscape evolution- } \\
\text { energy distribution probabilities } \\
\text { are as uniform as may be } \\
\text { permitted by physical constrains }\end{array}$ & Maximum entropy \\
\hline $\begin{array}{l}\text { A. Wilson, } \\
1970[3]\end{array}$ & Geography & $\begin{array}{l}\text { Spatial location and interaction } \\
\text { models }\end{array}$ & $\begin{array}{l}\text { People and things tend to be/go } \\
\text { everywhere unless constrained } \\
\text { to do otherwise }\end{array}$ \\
\hline $\begin{array}{l}\text { H. Thail, } \\
1972[16]\end{array}$ & Economy & Relative entropy & $\begin{array}{l}\text { Proportion of the maximum } \\
\text { uncertainty, spread, } \\
\text { dividedness. }\end{array}$ \\
\hline $\begin{array}{l}\text { M. Batty, } \\
1974[18]\end{array}$ & Geography & $\begin{array}{l}\text { Spatial entropy-incorporates } \\
\text { interval size to weight on the } \\
\text { probabilities }\end{array}$ & $\begin{array}{l}\text { Optimization of data categories, } \\
\text { or zones for visualization an } \\
\text { analysis. Trends in the spread of } \\
\text { probabilities across the spatial } \\
\text { system. }\end{array}$ \\
\hline $\begin{array}{l}\text { K. Bailey, } \\
1990[19]\end{array}$ & Sociology & $\begin{array}{l}\text { Social entropy measures diversity } \\
\text { among social parameters, opposes } \\
\text { social structure }\end{array}$ & $\begin{array}{l}\text { Low social entropy necessary to } \\
\text { maintain good standard } \\
\text { of living }\end{array}$ \\
\hline $\begin{array}{l}\text { J. Stepanić et al., } \\
2000[20]\end{array}$ & Sociology & Entropy of a social system & $\begin{array}{l}\text { Number of possible social } \\
\text { structures the system can adopt }\end{array}$ \\
\hline $\begin{array}{l}\text { F. Parisi, } \\
2002[21]\end{array}$ & Economy & Entropy in property & $\begin{array}{l}\text { Property is subject to the } \\
\text { fundamental law of entropy }\end{array}$ \\
\hline
\end{tabular}


This review demonstrates how elusive, ambiguous, and yet useful the entropy concept has been in describing the structure and behavior of different systems. Entropy is useful to measure the level of organization versus chaos, uniformity versus diversity, useful versus useless, or order versus disorder in different systems and in different scientific domains. It is also interesting to point out that entropy addresses three big features of urban structure and behavior: the position/location, the mechanic/flow networks, and system scaling/size.

\section{Urban Systems and Urban Sprawl}

\subsection{Urban Systems}

Many important European cities have made substantial layout changes following catastrophes, such as the modern urban plan of Lisbon after the Great Lisbon Earthquake in 1755 [23]. In 1852, Haussman remodeled medieval Paris, paying attention to all features of city planning in order to improve aesthetics, sanitation, and policing of the city [24]. However, it was the Catalan engineer Ildefons Cerdà who introduced scientific analysis to the city and its modern requirements to project the extension of Barcelona [25]. Cerdà produced the "General Theory of Urbanization" in 1867, in which the main requirements of the modern industrial city were identified: transport, communication, and growth. Urbanization was based on connectivity and networks. Instead of imposing a specific urban form, Cerdà proposed a set of parameters to articulate the urban fabric, i.e., the urban system, with various components and interactions.

A century later, Berry [26] perceived cities as spatial systems, viewing the urban theory as one aspect of the General Systems Theory. In 1970, Forrester identified the complexity of urban systems [27]. Cities are conceptualized as complex systems of interacting industry, housing, and people represented by variables and flows. However, Forrester's model is not explicitly spatial, as it focuses only on its economic and social aspects.

The study of complex systems has evolved rapidly in recent decades and has contributed to our understanding of cities [4]. It is currently accepted that complex systems are characterized not only by nonlinearity and stochastic processes, but also by the absence of central control [4]. Their behavior emerges from the interaction of multiple components. Robustness of structure and behavior is required to counteract perturbations in these systems. However, the notion of equilibrium is obsolete in this as in many other domains where time is considered [28]. The underlying mathematics of complex systems leads to some fascinating findings regarding the spatial evolution of urban systems and their morphologies at different scales, but their practical meaning remains elusive, although greater insights are anticipated for the near future.

\subsection{Urban Sprawl}

Urban areas are centers of economic and social development characterized by the mixture of residential, commercial, agricultural, and industrial activities. The uncontrolled expansion of urban areas is causing a wide range of social and environmental problems and has become a major concern for urban planners and policy makers in the developed and developing world [29-31]. 
Despite the considerable number of studies on this subject, there is no common definition of urban sprawl. Many have agreed that urban sprawl is an undesirable type of urban growth that favors the dispersal of new urban settlements with low density across space, rather than spatial aggregation of development [31-37]. Urban sprawl reduces landscape attractiveness [38], causes land use fragmentation and loss of biodiversity [39], and contributes to significant economic costs for infrastructural development [40] and public health problems [41,42]. Reference [43] summarized 40 years of research on the impacts of urban sprawl and concluded that the three conditions that define the negative impacts of sprawl are: leapfrog development, low-density, and unlimited outward expansion. According to [44], urban sprawl is characterized by an unplanned and uneven pattern of growth, driven by a multitude of processes that lead to inefficient resource utilization. As discussed by [34], urban sprawl is a process in which the spread of development across the landscape far outpaces population growth.

Urban sprawl studies are often undertaken with the goal of understanding what urban sprawl is exactly; to measure or quantify it; to study its causes and consequences; to identify the best methodology to analyze it; to predict the effects of sprawl when measures are not taken in a timely fashion; to propose satisfactory reasoning against the major factors contributing to sprawl; to find a solution that helps to achieve environmentally sustainable, socially acceptable, and economically viable urban development. Some research has sought to assess the major causes or driving forces [45-48], to measure and evaluate its impacts $[10,33,34,40]$, and to understand and plan sustainable urban growth $[29,34,44,47,49]$.

The objectives and approaches of urban studies vary from country to country. For example, in the United States [34] conducted a comprehensive statistical analysis of the 83 largest metropolitan areas' development patterns in order to measure urban sprawl and its impact on quality of life. The study grouped the sprawl index into four components: density, land use mix, strength of centers, and network accessibilities.

To understand urban sprawl from the European perspective, the authors of [8] investigated the drivers of European urban sprawl. They classified the driving forces into four categories: economy, society, transport, and political factors. Their study concluded that the driving forces vary among cities, countries, and regions. Moreover, they reported that the driving forces are closely connected with each other and that a clear cause-effect relationship on urban sprawl is unclear.

In China, according to [50,51] urban sprawl started some decades ago as a result of the government's land reform, which led to large and discontinuous urban areas, and to urban population growth resulting from migration inflows of those seeking employment and study opportunities. Similarly, a study in Eritrea, Africa [52] concluded that urban sprawl in Asmara occurred when the government land allocation system proved to be more powerful than the land use plan.

Unlike many researchers [53], discussed some positive effects of urban sprawl and mentioned increased satisfaction with housing, convenience of car travel, lower crime rates, and better public schools in suburban areas. The authors of this paper made a thorough review of urban sprawl, which is one of the major concerns of urban planners, designers, environmentalists, economists, and sociologists, among others.

We conclude that urban sprawl has no definition that satisfies all perspectives. In turn, it is not easy to identify a common methodology and approach to measure it. 


\subsection{Methods Used in Urban Sprawl Studies}

An urban area that is not sprawled can be described by its degree of compactness. Hence, it is necessary to measure the urban area at one moment in time, or the urban growth, i.e., its variation between two moments [44]. The first can be mapped into a single temporal image. The latter requires a minimum of two temporal images to detect the growth or the change.

Quantifying urban growth is a straightforward task. However, without having a common definition of urban sprawl, its quantification and modeling are very difficult [6]. Despite this difficulty, several studies have sought to quantify, measure the pattern, model and analyze the process of urban growth and sprawl.

One of the simplest and most popular methods is the transition matrix. This is a tabular measure of change between two land-use-cover classes obtained from remotely sensed image classification [7,54]. The transition matrix describes statistically the transition between the land-use-cover classes. The transition matrix is not helpful for performing sprawl analysis, however $[55,56]$.

Another popular technique is to use spatial metrics, also known as landscape metrics. As discussed by [7,11], combining the results of remote sensing and spatial metrics can yield a detailed understanding of the urban spatial structure and change. The application of these metrics in urban growth studies is growing because these help to reveal the spatial component in the urban structure, the urban dynamics of change, and the growth process [7,11]. Moreover, they have important functions in quantifying urban growth, sprawl, and fragmentation [57].

An additional method to analyze urban growth or sprawl is spatial statistics. For example, [58] have used statistical models to explain sprawl. In [59] a set of quantitative variables to analyze the characteristics of urban form to differentiate compactness from sprawl was used.

Finally, we return to entropy as a commonly used way to address urban sprawl. The concept has been applied to measure urban sprawl with the integration of remote sensing and geographic information systems (GIS) [9,17,37]. The calculation of Shannon's Entropy, an urban sprawl index using remotely sensed data can efficiently identify and characterize the degree of spatial concentration or dispersion in a specific area $[17,60]$.

\section{Entropy in Urban Systems: A Framework for Monitoring Entropy in Urban Sprawl}

Cities are systems in which multiple components are assembled to deliver the best possible conditions for human growth. Human growth is here understood as the increase in material, cultural, and human assets that contribute to better and longer lives of its inhabitants.

Urban systems' fundamental components are society (economy, culture, technology, and political organization) and space (area, natural resources, accessibilities, climate, networks, and internal arrangement of land use). However, delimiting the geographical space of an urban system is not at all straightforward $[61,62]$. The urban system cannot be confined to urban land classes. Surrounding land use/cover classes such as beaches, lakes, forests, and agricultural land are commonly used by people from urban areas. Moreover, these areas are a strong asset to the urban system, providing resources and assets for the inhabitants of the neighboring urban areas. More could be said about the social system of cities, but here we focus only on its geographical component, keeping in mind that the city 
spatial arrangement results necessarily from the interaction of society with the geographical conditions of its location.

Urban systems must satisfy two conditions to continue functioning: (i) they must efficiently deliver the material and cultural assets that allow for a better life of city's inhabitants; and (ii), the system should be resilient and flexible enough to adapt to internal and external changes or shocks. The first requires some spatial order and organization. Therefore, is desirable low entropy in transportation, utilities, services and in the arrangement of built-up areas. However, some redundancy and diversity (entropy) in the urban geography is required, so that the city can better resist long-tail events likely to compromise its functioning (natural catastrophes, man-made events, or both).

This line of thought leads us to conclude that for all dimensions of the urban systems, there is a range of values in which entropy could be tolerated without compromising its efficiency and/or its resilience (Figure 1). If entropy falls below $\mathrm{H}_{\mathrm{Min}}$, then the urban area is too uniform and, therefore, vulnerable to changes or power laws; if entropy exceeds $\mathrm{H}_{\mathrm{Max}}$, then the urban system will be unable to efficiently allocate the necessary resources for the system to function.

Figure 1. Desirable interval of fluctuation for entropy values in urban system.

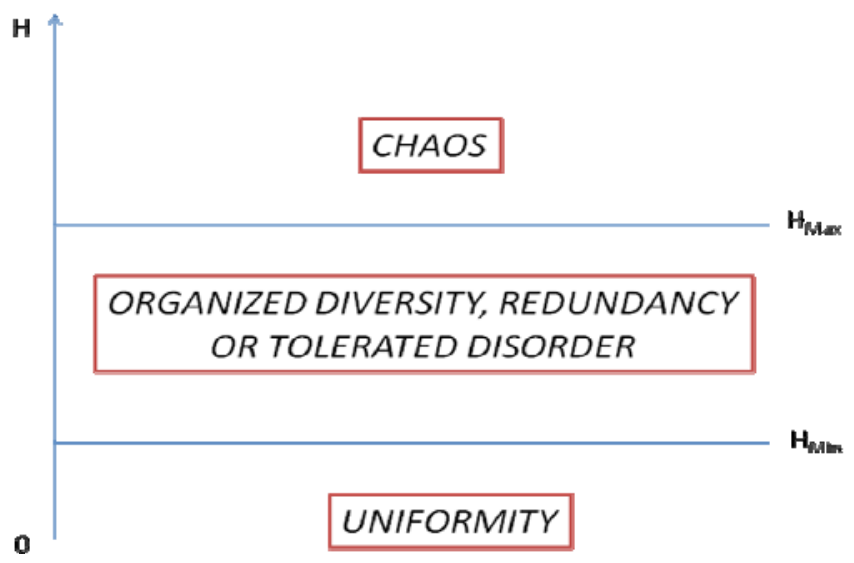

In recent decades the concept of cities as top-down organized systems has given place to cities as complex systems. These are more comparable to biological organisms, in which morphology and evolution emerge from a multitude of interactions among their components [63]. Rapidly expanding urban systems often develop on their own accord, and attempts to control urban systems sometimes have undesirable effects.

Urban sprawl calls for the special attention of city planners and policy makers to the following things: (i) urban sprawl requires adequate location of the new infrastructures to ensure that the urban system keeps delivering the necessary services for the well-being of newly settled populations; (ii) urbanization is an irreversible process, and unchecked urbanization may decrease the quality or resilience of the urban system by compromising natural and/or ecosystem services; and (iii) newly urbanized areas often attract homogenous groups of population, exposing the whole system to new vulnerabilities.

For policy makers the complex nature of urban systems and their growth leave little room for urban planning as conceived half a century ago. Still, the introduction of some territorial constraints and the monitoring of entropy levels of the system may enable the city administration to prevent or mitigate 
inefficiencies or dangerous vulnerabilities. Thus, entropy measures are valuable indicators of the performance and risks in urban systems (Figure 2).

Figure 2. Urban sprawl entropy monitoring framework. $\mathrm{H}$ is entropy, $\mathrm{N}$ is geographical zone, and $\mathrm{k}$ is the subsystem (social, environment, etc.).

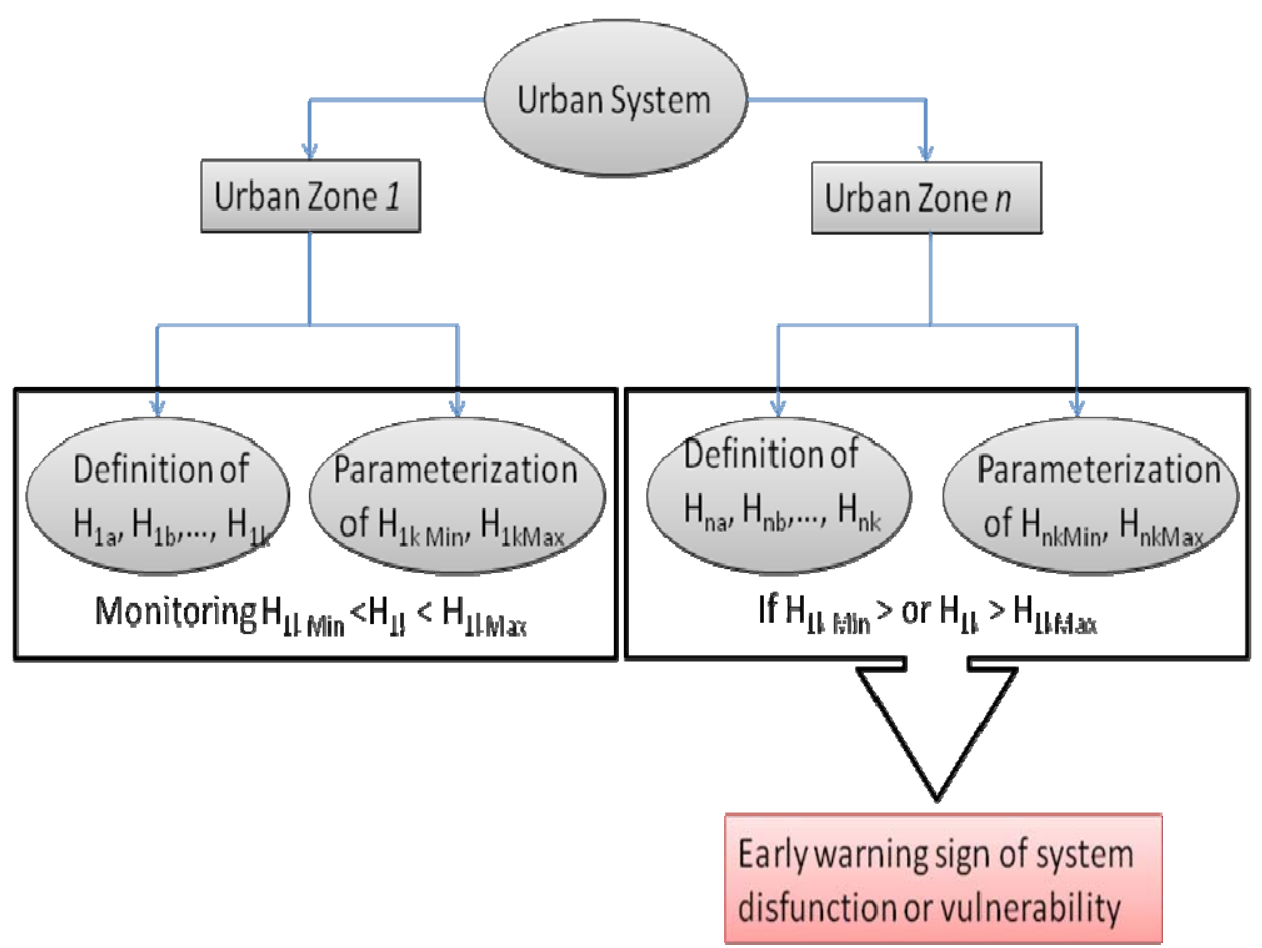

For instance, if too many buildings are becoming old (low entropy), the city managers should intervene before obsolescence causes the depression of the real estate value of the entire area, thereby inviting a host of associated socio-economic problems. If, on the other hand, noisy businesses are settled in peaceful residential areas (high entropy); the value of real estate may similarly be degraded.

The entropy among urban zones or subsystems follows the same reasoning, i.e., high levels of entropy are very demanding for transport and other infrastructures, whereas low entropy levels increase the risk of social and economic segregation, thus endangering the cohesion of the urban system.

\section{Conclusions}

In the unassailable closed thermodynamic system of Clausius, entropy increases up to the point in which the system can no longer produce work. In any open system, an increase of work necessarily implies an increase of entropy, and the production level can be maintained only if the system expands. Urban growth is, therefore, a necessary condition for the urban system to prevail. In the complex and interrelated processes involved in urban growth and sprawl, entropy must be kept within a range defined by the minimum value, below which the system becomes vulnerable and unstable, and the maximum value, above which the system becomes unsustainable. The parameterization of those thresholds may be very useful for urban administrations, thus providing valuable insights into the functioning of urban systems. 


\section{Acknowledgment}

We are thankful to the reviewers for their constructive comments which lead to the improvement of the paper.

\section{Conflicts of Interest}

The authors declare no conflict of interest.

\section{References}

1. Uffink, J. Bluff your way in the second law of thermodynamics. Stud. Hist. Philos. Sci. Part B: Stud. Hist. Philos. Mod. Phys. 2001, 32, 305-394.

2. Millennium Ecosystem Assessment. Ecosystems and Human Well-Being: Synthesis; Island Press: Washington, DC, USA, 2005.

3. Wilson, A. Entropy in urban and regional modelling: Retrospect and prospect. Geogr. Anal. 2010, 42, 364-394.

4. Batty, M. Building a science of cities. Cities 2012, 29, S9-S16.

5. Niemelä, J.; Saarela, S.-R.; Söderman, T.; Kopperoinen, L.; Yli-Pelkonen, V.; Väre, S.; Kotze, D.J. Using the ecosystem services approach for better planning and conservation of urban green spaces: A Finland case study. Biodivers. Conserv. 2010, 19, 3225-3243.

6. Hoffhine Wilson, E.; Hurd, J.D.; Civco, D.L.; Prisloe, M.P.; Arnold, C. Development of a geospatial model to quantify, describe and map urban growth. Remote Sens. Environ. 2003, 86, 275-285.

7. Herold, M.; Couclelis, H.; Clarke, K.C. The role of spatial metrics in the analysis and modeling of urban land use change. Comput. Environ. Urban Syst. 2005, 29, 369-399.

8. Christiansen, P.; Loftsgarden, T. Drivers behind Urban Sprawl in Europe; Institute of Transport Economics, Norwegian Centre of Transport Research: Oslo, Norway, 2011; p. 29.

9. Sun, H.; Forsythe, W.; Waters, N. Modeling urban land use change and urban sprawl: Calgary, Alberta, Canada. Networks Spat. Econ. 2007, 7, 353-376.

10. Martins, V.N.; Pires, R.; Cabral, P. Modelling of coastal vulnerability in the stretch between the beaches of Porto de Mós and Falésia, Algarve (Portugal). J. Coast. Conserv. 2012, 16, 503-510.

11. Cabral, P.; Santos, J.A.; Augusto, G. Monitoring urban sprawl and the national ecological reserve in Sintra-Cascais, Portugal: Multiple OLS linear regression model evaluation. J. Urban Plan. Dev. 2011, 137, 346-353.

12. Clausius, R. The Mechanical Theory of Heat: With its Applications to the Steam-Engine and to the Physical Properties of Bodies; J. Van Voorst: London, UK, 1867; p. 376.

13. Jaynes, E.T. Information Theory and Statistical Mechanics. Phys. Rev. 1957, 106, 620-630.

14. Shannon, C.E. A mathematical theory of communication. Bell Syst. Tech. J. 1948, 27, 379-423.

15. Leopold, L.B.; Langbein, W.B. The Concept of Entropy in Landscape Evolution; United States Geological Survey: Washington, DC, USA, 1962.

16. Thomas, R.W. Information Statistics in Geography; Headey Brothers Ltd, The Invicta Press: Ashford, Kent, UK, 1981. 
17. Yeh, A.G.O.; Li, X. Measurement and monitoring of urban sprawl in a rapidly growing region using entropy. Photogramm. Eng. Remote Sens. 2001, 67, 83-90.

18. Batty, M. Spatial entropy. Geogr. Anal. 1974, 6, 1-31.

19. Bailey, K.D. Social entropy theory: An overview. Syst. Pract. 1990, 3, 365-382.

20. Stepanic, J.; Stefancic, H.; Zebec, M.S.; Perackovic, K. Approach to a quantitative description of social systems based on thermodynamic formalism. Entropy 2000, 2, 98-105.

21. Parisi, F. Entropy in property. Am. J. Comp. L. 2002, 50, 595-632.

22. Miceli, T.J.; Sirmans, C.F. The holdout problem, urban sprawl, and eminent domain. J. Housing Econ. 2007, 16, 309-319.

23. The 1755 Lisbon Earthquake: Revisited. In Geotechnical, Geological, and Earthquake Engineering; Springer: Dordrecht, The Netherlands, 2009.

24. Wagenaar, M. Townscapes of power. GeoJournal 2000, 51, 3-13.

25. Cerdà, I. Teoría General de la Urbanización, 1: y Aplicación de sus Principios y Doctrinas a la Reforma y Ensanche de Barcelona (in Spanish); Imprenta Española: Madrid, Spain, 1867.

26. Berry, B.J.L. Cities as systems within systems of cities. Pap. Reg. Sci. 2005, 13, 147-163.

27. Forrester, J. Systems analysis as a tool for urban planning. IEEE Trans. Syst. Sci. Cybern. 1970, 6, 258-265.

28. Sterman, J. Business Dynamics: Systems Thinking and Modeling for a Complex World; Irwin/McGraw Hill Higher Education: Columbus, OH, USA, 2000.

29. Knaap, G.; Talen, E.; Olshansky, R.; Forrest, C. Government Policy and Urban Sprawl; Illinois Department of Natural Resources, Office of Realty and Environmental Planning: Chicago, IL, USA, 2013.

30. Frenkel, A.; Ashkenazi, M. The integrated sprawl index: Measuring the urban landscape in Israel. Ann. Reg. Sci. 2007, 42, 99-121.

31. Brueckner, J.K. Urban sprawl: Diagnosis and remedies. Int. Reg. Sci. Rev. 2000, 23, 160-171.

32. Yeh, A.; Xia, L. Integration of neural networks and cellular automata for urban planning. Geo-Spat. Inf. Sci. 2004, 7, 6-13.

33. Johnson, M.P. Environmental impacts of urban sprawl: A survey of the literature and proposed research agenda. Environ. Plan. 2001, 33, 717-735.

34. Ewing, R.H. Characteristics, Causes, and Effects of Sprawl: A Literature Review. In Urban Ecology; Marzluff, J.M., Shulenberger, E., Endlicher, W., Alberti, M., Bradley, G., Ryan, C., Simon, U., ZumBrunnen, C., Eds.; Springer US: Boston, MA, USA, 2008; pp. 519-535.

35. Nechyba, T.J.; Walsh, R.P. Urban sprawl. J. Econ. Perspect. 2004, 18, 177-200.

36. Zhang, Y.; Yang, Z.; Li, W. Analyses of urban ecosystem based on information entropy. Ecol. Model. 2006, 197, 1-12.

37. Bhatta, B.; Saraswati, S.; Bandyopadhyay, D. Quantifying the degree-of-freedom, degree-of-sprawl, and degree-of-goodness of urban growth from remote sensing data. Appl. Geogr. 2010, 30, 96-111.

38. Sullivan, W.C.; Lovell, S.T. Improving the visual quality of commercial development at the rural-urban fringe. Landsc. Urban Plan. 2006, 77, 152-166.

39. Alberti, M. The effects of urban patterns on ecosystem function. Int. Reg. Sci. Rev. 2005, 28, 168-192. 
40. Burchell, R.W.; Mukherji, S. Conventional development versus managed growth: The costs of sprawl. Am. J. Public Health 2003, 93, 1534-1540.

41. Sturm, R.; Cohen, D.A. Suburban sprawl and physical and mental health. Public Health 2004, $118,488-496$.

42. Kelly-Schwartz, A.C. Is sprawl unhealthy? A multilevel analysis of the relationship of metropolitan sprawl to the health of individuals. J. Plan. Educ. Res. 2004, 24, 184-196.

43. Burchell, R.; Shad, N.; Listokin, D.; Phillips, H.; Downs, A.; Seskin, S.; Davis, J.; Moore, T.; Helton, D.; Gall, M. The costs of sprawl-revisited; Transit Cooperative Research Program: Washington, DC, USA, 1998; p. 40.

44. Bhatta, B. Analysis of Urban Growth and Sprawl from Remote Sensing Data; Advances in Geographic Information Science; Springer: Heidelberg, Germany and New York, NY, USA, 2010.

45. Yang, X.; Lo, C.P. Modelling urban growth and landscape changes in the Atlanta metropolitan area. Int. J. Geogr. Inf. Sci. 2003, 17, 463-488.

46. Cheng, J.; Masser, I. Urban growth pattern modeling: A case study of Wuhan city, PR China. Landsc. Urban Plan. 2003, 62, 199-217.

47. Burchfield, M.; Overman, H.G.; Puga, D.; Turner, M.A. Causes of sprawl: A portrait from space. Q. J. Econ. 2006, 121, 587-633.

48. Squires, G. Urban Sprawl: Causes, Consequences, \& Policy Responses; Urban Institute Press: Washington, DC, USA, 2002.

49. Martins, V.N.; Silva, D.S.E.; Cabral, P. Social vulnerability assessment to seismic risk using multicriteria analysis: The case study of Vila Franca do Campo (São Miguel Island, Azores, Portugal). Nat. Hazards 2012, 62, 385-404.

50. Wu, F. Urban Development in Post-Reform China: State, Market, and Space; Routledge: Abingdon, Oxon, UK and New York, NY, USA, 2007.

51. Frederic Deng, F.; Huang, Y. Uneven land reform and urban sprawl in China: The case of Beijing. Prog. Plan. 2004, 61, 211-236.

52. Tewolde, M.G.; Cabral, P. Urban sprawl analysis and modeling in Asmara, Eritrea. Remote Sens. 2011, 3, 2148-2165.

53. Robert, W. Wassmer causes of urban sprawl in the United States: Auto reliance as compared to natural evolution, flight from blight, and local revenue reliance. J. Policy Anal. Manage. 2008, 27, $536-555$.

54. Jensen, J.R. Introductory Digital Image Processing: A Remote Sensing Perspective, 2nd ed.; Prentice Hall: Upper Saddle River, NJ, United States, 1996.

55. Angel, S.; Sheppard, S.; Civco, D. The Dynamics of Global Urban Expansion; Transport and Urban Development Department, The World Bank: Washington, DC, USA, 2005.

56. Almeida, C.M.D.; Monteiro, A.M.V.; Câmara, G.; Soares-Filho, B.S.; Cerqueira, G.C.; Pennachin, C.L.; Batty, M. GIS and remote sensing as tools for the simulation of urban land-use change. Int. J. Remote Sens. 2005, 26, 759-774.

57. Hardin, P.J.; Jackson, M.W.; Otterstrom, S.M. Mapping, Measuring, and Modeling Urban Growth. In Geo-Spatial Technologies in Urban Environments; Jensen, D.R.R., Gatrell, D.J.D., McLean, D.D., Eds.; Springer: Berlin/Heidelberg, Germany, 2007; pp. 141-176. 
58. Torrens, P.; Alberti, M. Measuring Urban Sprawl; Working Paper Series; Centre for Advances Spatial Analysis, University College London: London, UK, 2000.

59. Tsai, Y.-H. Quantifying urban form: Compactness versus "sprawl." Urban Stud. 2005, 42, 141-161.

60. Araya, Y.H.; Cabral, P. Analysis and modeling of urban land cover change in Setúbal and Sesimbra, Portugal. Remote Sens. 2010, 2, 1549-1563.

61. Herold, M.; Scepan, J.; Clarke, K.C. The use of remote sensing and landscape metrics to describe structures and changes in urban land uses. Environ. Plan. 2002, 34, 1443-1458.

62. Cabral, P. Délimitation d'aires urbaines à partir d'une image Landsat ETM+: Comparaison de méthodes de classification. Can. J. Remote Sens. 2007, 33, 422-430, (in French).

63. Portugali, J. Self-Organization and the City; Springer Series in Synergetics; Springer: New York, NY, USA, 1999.

(C) 2013 by the authors; licensee MDPI, Basel, Switzerland. This article is an open access article distributed under the terms and conditions of the Creative Commons Attribution license (http://creativecommons.org/licenses/by/3.0/). 